\title{
Entrevista - Nilma Lino Gomes
}

Belo Horizonte (MG), 6 de maio de 2013

Wilma Baía Coelho*

Patrícia Melo Sampaio**

Nilma Lino Gomes é pedagoga e mestre em Educação (UFMG), doutora em Antropologia Social (USP) e pós-doutora em Sociologia pela Universidade de Coimbra. É professora da graduação e pós-graduação da Faculdade de Educação (FaE) da UFMG. Coordena o Núcleo de Estudos e Pesquisas sobre Relações étnico-raciais e Ações Afirmativas (NERA) e o GT21 Educação e Relações Étnico-raciais da Anped (2012-2013). É membro da Associação Brasileira de Pesquisadores Negros (ABPN) e integrante da Câmara de Educação Básica do Conselho Nacional de Educação (CNE). Atualmente, é reitora da Universidade da Integração Internacional da Lusofonia Afro-Brasileira (Unilab).

\section{Professora, a senhora poderia sintetizar a sua trajetória acadêmica?}

Sou uma educadora. Sempre fui educadora, desde que me formei no Instituto de Educação de Minas Gerais, no Ensino Médio. Após anos de docência na educação básica, fiz vestibular para o curso de Pedagogia na UFMG e a partir daí novas questões educacionais me foram colocadas.

Foi na vivência real da relação entre teoria e prática presente na minha atuação como docente da educação infantil e dos anos iniciais do ensino fundamental, bem como no meu envolvimento com a pesquisa durante a graduação que a questão racial - presente na minha própria história de vida - emergiu como uma questão pedagógica, de pesquisa e política. Esse processo complexo me instigou a buscar o mestrado em educação.

\footnotetext{
** Faculdade de História, Instituto de Filosofia, Ciências Humanas e Sociais da Universidade Federal do Pará (UFPA). Av. Augusto Correa, 1, Guamá. 66075.110 Belém - PA - Brasil. wilmacoelho@yahoo.com.br

** Departamento de História, Instituto de Ciências Humanas e Letras, Universidade Federal do Amazonas (UFAM). Av. Rodrigo Otávio, Setor Norte, Campus Universitário, Coroado. 69080005 Manaus - AM - Brasil. patrícia@pq.cnpq.br
} 
Após o mestrado, passei a ter uma compreensão mais densa dos processos educacionais e sua articulação com a questão étnico-racial. Paralelamente, a vivência como educadora da Rede Municipal de Ensino, a experiência de participar da implementação da proposta político-pedagógica Escola Plural, em Belo Horizonte, e os desafios dela advindos me motivaram a prestar concurso como docente na Faculdade de Educação da UFMG. Ao ser aprovada, dei continuidade como professora e pesquisadora às discussões sobre educação, cultura e movimentos sociais, com enfoque nas questões étnico-raciais. Essa escolha me acompanhou no doutorado e no pós-doutorado e continua sendo um eixo orientador da minha atuação até hoje.

Ao longo da minha trajetória profissional e de pesquisa, a preocupação com a formação de professores e a diversidade étnico-racial, a organização de ações e políticas antirracistas têm sido características marcantes. Junto a colegas da FaE [Faculdade de Educação], da ECI [Escola de Ciência da Informação] e do Centro Pedagógico da UFMG criamos o Programa de Pesquisa, Ensino e Extensão Ações Afirmativas na UFMG, o qual há 10 anos tem uma ação de intervenção na formação acadêmica de estudantes negros e de baixa renda dessa universidade, bem como tem sido um polo de realização de pesquisas e ações de formação continuada de docentes da Educação Básica, em Belo Horizonte.

Essa ação acadêmico-política contribuiu para a minha indicação como representante do Movimento Negro na Câmara de Educação Básica do CNE [Conselho Nacional de Educação]. Penso que tudo isso, de alguma forma, também contribuiu para a minha nomeação pelo ministro da Educação como reitora Pro Tempore da Universidade da Integração Internacional da Lusofonia AfroBrasileira (Unilab). Mas uma coisa é certa: não se trata de uma trajetória individual, construída no isolamento. Ela é fruto da nossa herança ancestral, dos elos Brasil/África, da formação que recebi da minha família, do processo educativo vivido no movimento negro e do trabalho coletivo que venho desenvolvendo ao longo dos anos, do qual participam tantos parceiros e parceiras.

Sua atuação acadêmica foi influenciada de alguma maneira pela formação recebida na Educação Básica?

Sim. Foi como mulher negra e professora da educação básica que passei a enxergar a presença da questão racial nos processos educativos, as tensões 
entre a identidade étnico-racial e a superação de estereótipos, o racismo, o preconceito e a discriminação racial, bem como a necessidade de construção de uma pedagogia antirracista e voltada para a diversidade. Fui educada e reeducada na minha atuação acadêmica pela prática pedagógica na Educação Básica e pelo Movimento Negro.

Como a senhora percebe a formação oferecida pelas escolas brasileiras hoje, considerando, especialmente o Ensino Fundamental?

Acho que as educadoras e os educadores do Ensino Fundamental, sobretudo das escolas públicas, são profissionais de luta. A cada ano, a educação se torna mais complexa porque a vida social tem se tornado de alta complexidade. A formação que se exige, hoje, sobretudo para aqueles que irão atuar no Ensino Fundamental, é muito diferente da minha época. Os estudantes são outros, e os docentes também.

Todavia, persistem velhas estruturas escolares excludentes, condições de trabalho indignas, falta de uma real política de valorização do magistério e salários injustos. Haja vista os argumentos de vários estados e municípios para o não cumprimento da lei do piso salarial do magistério da Educação Básica. Sabemos das implicações, das diferentes situações e condições estruturais, econômicas, geográficas e políticas dos entes federados, mas nada justifica a indisposição a que assistimos por parte de alguns gestores públicos quanto ao pagamento do piso salarial do magistério. Isso tem implicações na prática pedagógica e na formação ofertada pelas escolas brasileiras.

Outra questão é a mudança estrutural e curricular necessária às licenciaturas para oferta de uma formação inicial condizente com as demandas educacionais do nosso tempo e com o perfil de docente exigido, hoje, tanto na rede pública quanto da rede privada. Da mesma forma, os currículos em ação das escolas de Educação Básica precisam ser outros e são instados a dialogar com a comunidade real levando em consideração não somente as avaliações sistêmicas e os índices de alfabetização e matematização, mas, também, as vivências, as experiências e as realidades da educação básica atual. Considerando, também, a tensa e necessária articulação entre desigualdades e diversidade.

Temos, hoje, avançado no entendimento da educação como direito social e humano, e isso implica lidar, administrar e considerar a convivência dentro dos sistemas de ensino de escolas urbanas, indígenas, quilombolas e do campo. 
Tudo isso se organiza nos níveis e modalidades de educação, o que está a exigir outra forma de administrar a escola básica e outra formação a ser ministrada aos educandos. Exige, também, propostas curriculares diversificadas e inovadoras que articulem dimensões pedagógicas comuns e realidades específicas.

Portanto, vejo a Educação Básica e não somente o Ensino Fundamental da atualidade diante de novos desafios trazidos não só pelas mudanças do ponto de vista teórico e da pesquisa como, também, pelas transformações sociais nacionais e internacionais. Há novos enfoques e práticas no campo das políticas públicas de combate a pobreza, e convivemos hoje com políticas universais e com as ações afirmativas. Os sujeitos sociais que antes estavam fora da educação escolar se encontram, hoje, no interior das nossas instituições, sobretudo as públicas. Quanto mais o direito à educação avança, mais os coletivos sociais diversos e tratados historicamente como desiguais passam a fazer parte do cotidiano escolar. Que escola eles querem? Que tipo de educação os atende? Que currículos construir? Como ampliar as formas de participação? Que sujeitos desejamos formar? São perguntas de sempre, mas que hoje exigem respostas diferentes.

Tudo isso impacta a formação ofertada pelas escolas brasileiras e exige mudanças na estrutura, nos currículos, na organização dos tempos e espaços escolares, na concepção de aprendizagem e nas metodologias de ensino. Podemos dizer que as nossas escolas estão impactadas por esse processo. Aquelas que se abrem para essa nova conjuntura, que se mostram abertas ao diálogo com a comunidade e com os movimentos sociais, possibilitando mudanças pedagógicas, políticas, curriculares e na gestão da escola, dão passos mais bem-sucedidos. Aquelas que resistem e mantêm posições conservadoras apresentam maiores problemas. Aquelas que recebem apoio e suporte da gestão do sistema de ensino e da escola conseguem dar passos mais interessantes. Aquelas que funcionam sem uma intervenção política emancipatória da gestão e do coletivo de profissionais e ainda se fecham à comunidade e aos movimentos sociais enfrentam sérios problemas.

Qual sua avaliação da aplicação da Lei 10.639/2003 na Educação Básica, passados 10 anos de sua criação?

Acho que já avançamos. Não sou partícipe do discurso de que 'nada mudou'. Porém, tenho uma leitura crítica do grau de alcance do que chamo de avanço. A implementação da alteração da LDB [Lei de Diretrizes e Bases da 
Educação Nacional] trazida pela Lei 10.639/03 ainda não corresponde à radicalidade da demanda que a originou. Há todo um processo irregular de enraizamento da referida lei nos sistemas de ensino, na formação de professores e nas escolas públicas e privadas.

Avançamos mais no público do que no privado. Isso tem a ver com questões estruturais, financeiras, e com a gestão da escola e do sistema. Mas tem também uma profunda relação com o imaginário sociorracial brasileiro que se expressa na escola. A predominância do mito da democracia racial e a ambiguidade do racismo brasileiro presentes na sociedade e na escola colocam empecilhos para a implementação da alteração da LDB pela Lei 10.639/03, bem como para o atendimento da Resolução CNE/CP 01/2004 e do Parecer CNE/ CP 03/2004.

As escolas, hoje, possuem diretrizes curriculares nacionais, emanadas pelo Conselho Nacional de Educação, as quais são orientadoras das práticas e do processo de implementação da temática afro-brasileira e africana e da educação das relações étnico-raciais na Educação Básica. Há também um Plano Nacional de Implementação das Diretrizes Curriculares Nacionais para a Educação das Relações Étnico-Raciais e para o Ensino de História e Cultura Afro-Brasileira e Africana. Todavia, ainda há um desconhecimento desse processo, e muitos cursos de licenciatura que deveriam estudar, divulgar, conhecer e socializar todo esse aparato legal de reconhecimento à diversidade étnico-racial ainda se isentam da sua responsabilidade.

Tal situação exige ainda pressão dos movimentos sociais, dos Núcleos de Estudos Afro-Brasileiros e dos Fóruns de Educação e Diversidade ÉtnicoRacial, bem como dos demais partícipes da luta antirracista para que o cumprimento da LDB se faça uma realidade para todos e possamos dar passos mais avançados na superação dessa situação irregular de implementação da legislação nos próximos anos.

Qual o papel das Universidades na construção de uma sociedade que respeita a diversidade? Qual o balanço que a senhora faz desse processo no ensino superior brasileiro considerando a diversidade de experiências que existem no Brasil?

Penso que o papel da universidade é produzir conhecimento numa perspectiva emancipatória. É superar as concepções conservadoras de ciência. É se abrir para o diálogo franco e aberto com a sociedade e, nesta, com os 
movimentos sociais e demais organizações da sociedade civil. A universidade - sobretudo a pública - deveria ser exemplo de instituição educativa e produtora de conhecimento capaz de reconhecer e valorizar as múltiplas formas e condições de produção de conhecimento.

Nos últimos anos, a universidade é instada, cada vez mais, a produzir conhecimento, tecnologias e pesquisas que articulem a ciência e os conhecimentos construídos pelos setores populares e comunidades tradicionais. Mas isso não é uma tarefa fácil. Já temos algumas experiências acadêmicas e de pesquisa que caminham nessa direção, mas não é possível afirmar que essa seja a visão hegemônica entre os dirigentes de educação superior e dentro da própria comunidade científica.

Como a senhora avalia a distinção dos percursos curriculares da Licenciatura e do Bacharelado, estabelecida pela Legislação?

Há tentativas de superar essa distinção, mas não é simples. No momento, eu diria que se a divisão entre licenciatura e bacharelado privilegiar a visão conservadora de que uns são aptos para o fazer prático e outros são feitos para pensar e produzir pesquisa, então ela está equivocada. Se essa for a concepção de fundo dessa distinção, então não formaremos nem bons licenciados nem bons bacharéis, pois a sua formação estará pautada em um 'vício de origem’ estrutural.

Esse processo acaba gerando uma distinção entre os próprios estudantes e quase que determina a sua trajetória acadêmica impondo um perfil estereotipado de graduando, proporcionando-lhes um currículo cindido no qual a pesquisa e a prática pedagógica se apresentam desarticuladas. Isso é muito sério. Sabemos, lamentavelmente, que essa cisão ainda é uma tendência muito forte na formação em nível superior brasileira.

Mas há experiências inovadoras em curso, as quais sinalizam outra forma de organização curricular e de prática pedagógica e científica. Precisamos torná-las públicas para conhecê-las, discuti-las e analisá-las, dando-lhes a devida visibilidade.

Entrevista recebida em 24 de maio de 2013. Aprovada em 24 de maio de 2013. 